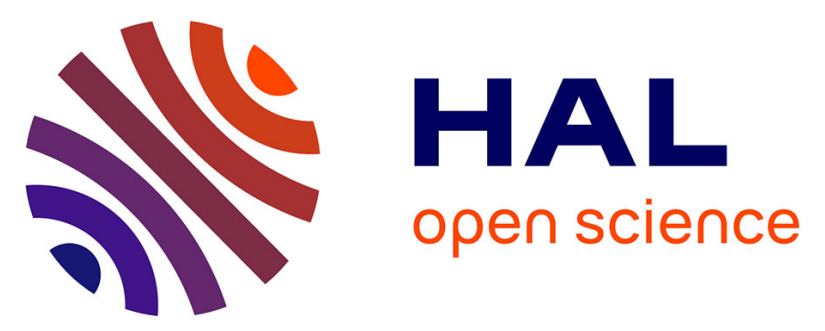

\title{
Effect of gamma rays absorbed doses and heat treatment on the optical absorption spectra of silver ion-exchanged silicate glass
}

Khaled Farah, Faouzi Hosni, Arbi Mejri, Bruno Boizot, Ben Hafedh, Ahmed Hichem Hamzaoui

\section{To cite this version:}

Khaled Farah, Faouzi Hosni, Arbi Mejri, Bruno Boizot, Ben Hafedh, et al.. Effect of gamma rays absorbed doses and heat treatment on the optical absorption spectra of silver ion-exchanged silicate glass. Nuclear Instruments and Methods in Physics Research Section B: Beam Interactions with Materials and Atoms, 2014, 323, pp.36-41. 10.1016/j.nimb.2014.01.019 . cea-01120984

\section{HAL Id: cea-01120984 https://hal-cea.archives-ouvertes.fr/cea-01120984}

Submitted on 27 Feb 2015

HAL is a multi-disciplinary open access archive for the deposit and dissemination of scientific research documents, whether they are published or not. The documents may come from teaching and research institutions in France or abroad, or from public or private research centers.
L'archive ouverte pluridisciplinaire HAL, est destinée au dépôt et à la diffusion de documents scientifiques de niveau recherche, publiés ou non, émanant des établissements d'enseignement et de recherche français ou étrangers, des laboratoires publics ou privés. 


\title{
Effect of gamma rays absorbed doses and heat treatment on the optical absorption spectra of silver ion-exchanged silicate glass
}

\author{
Khaled Farah ${ }^{\mathrm{a}, \mathrm{b}, *}$, Faouzi Hosni ${ }^{\mathrm{a}, \mathrm{c}}$, Arbi Mejri ${ }^{\mathrm{a}}$, Bruno Boizot ${ }^{\mathrm{d}}$, Ahmed Hichem Hamzaoui ${ }^{\mathrm{e}}$, \\ Hafedh Ben Ouada ${ }^{\mathrm{f}}$

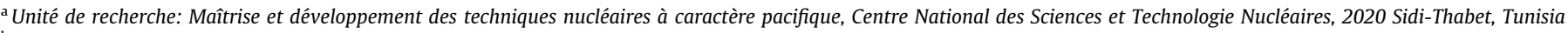 \\ ${ }^{\mathrm{b}}$ ISTLS, University of Sousse, Tunisia \\ ${ }^{\mathrm{c}}$ Academie Militaire de Fondouk Jedid, 8012 Nabeul, Tunisia \\ ${ }^{\mathrm{d}}$ Laboratoire des Solides Irradiés, Ecole Polytechnique, Route de Saclay, 91128 Palaiseau Cedex, France \\ ${ }^{\text {e } C e n t r e ~ N a t i o n a l ~ d e ~ R e c h e r c h e ~ e n ~ S c i e n c e s ~ d e s ~ M a t e ́ r i a u x, ~ B . P . ~ 95, ~ H a m m a m-L i f ~ 2050, ~ T u n i s i a ~}$ \\ ${ }^{\mathrm{f}}$ Laboratoire des Interfaces et Matériaux Avancés, Faculté des Sciences, University of Monastir, Avenue de l'environnement, 5019 Monastir, Tunisia
}

\section{A R T I C L E I N F O}

\section{Article history:}

Received 10 May 2013

Received in revised form 28 December 2013

\section{Keywords:}

Silicate glass

Ion-exchange

Gamma rays

Absorbed doses thermal annealing

Optical absorption spectra

Silver nanoparticles

\begin{abstract}
A B S T R A C T
Samples of a commercial silicate glass have been subjected to ion exchange at $320^{\circ} \mathrm{C}$ in a molten mixture of $\mathrm{AgNO}_{3}$ and $\mathrm{NaNO}_{3}$ with molar ratio of 1:99 and 5:95 for $60 \mathrm{~min}$. The ion exchange process was followed by gamma irradiation in the dose range of $1-250 \mathrm{kGy}$ and heating at the temperature of $550{ }^{\circ} \mathrm{C}$ for different time periods ranging from 10 to $582 \mathrm{~min}$. The spectral absorption in UV-Vis range of the Ag-Na ion exchanged glass was measured and used to determine the states of silver prevailing in the glass during the ion exchange, the gamma irradiation and the heat treatment. The gamma irradiation induced holes and electrons in the glass structure leading to the creation of a brown colour, and silver ions trapped electrons to form silver atoms. We observed the first stage of aggregation after irradiation, as well as after heating. The silver atoms diffused and then aggregated to form nanoclusters after heating at $550^{\circ} \mathrm{C}$. A characteristic band at about $430 \mathrm{~nm}$ was induced. The surface Plasmon absorption of silver nanoclusters in the glass indicated that the nanoclusters radius grew between 0.9 and $1.43 \mathrm{~nm}$ with increasing of annealing time from 10 to $242 \mathrm{~min}$ and then saturated. We also found that the size of aggregates depends on the value of gamma radiation absorbed dose. Contrary to what was expected, we found that $20 \mathrm{kGy}$ is the optimal absorbed dose corresponding to the larger size of the aggregates which decreases for absorbed doses above $20 \mathrm{kGy}$.
\end{abstract}

(c) 2014 Elsevier B.V. All rights reserved.

\section{Introduction}

Small silver particles embedded in glass matrix are widely studied because of their potential applications for glass colouration $[1,2]$ for ionizing radiation dosimetry [3] and recently for fabricating optical devices [4]. The ion exchange has been considered one of the most important techniques to introduce noble metals in glass surface. This technique is simple, and does not require sophisticated equipments. Combined with a heat treatment, the ion exchange technique has received an increase attention as it can be used to introduce metallic nanosize particles such silver, gold and copper into glass matrix [5-7]. Recently ionizing radiation such as gamma rays, electrons, heavy ions, X-ray or laser beam, has been used, with or instead of the heat treatment, to produce silver

* Corresponding author at: ISTLS, University of Sousse, Tunisia. Tel.: +216 55257099.

E-mail address: kafarah@gmail.com (K. Farah). colloids after the ion exchange in glass [8-11]. Ionizing radiation produces in insulating materials electron hole pairs (excitons) which lead to the production of stable defects and changes of the valence state of doping and impurities ions in the glasses. The production of irradiation defects cause preferential light absorption and consequently these defects are called "colour centres". These centres are of many types and depending on the glass composition and can be analyzed using optical absorption bands and EPR lines.

Gamma irradiation effects in silicate glass have been studied in our previous papers [12,13].

Only few works have been reported in the literature about the combined role of gamma irradiation and heat treatment on the formation of silver nanoparticles in ion exchanged glass.

Further investigations will be necessary to shed light on the relationship between the absorbed dose of gamma radiation and the properties of UV-visible spectra of silver ion-exchanged silicate glass. Our observations indicate that the first stage of aggregation can occur after irradiation before the heat treatment. We have 
observed that gamma irradiation followed by the heat treatment of an ion exchanged silicate glass can effectively promote silver migration and aggregation of metallic nanocluster. The effect of absorbed dose variation on the size of the aggregates has also investigated. In our knowledge, this effect had not been reported in previous work.

\section{Experimental}

\subsection{Glass composition}

The glass samples were obtained from the same glass sheets purchased from the local market and were cut into pieces of $11 \times 30 \times 1.5 \mathrm{~mm}^{3}$ dimensions for optical measurements. The chemical composition of the glass samples were determined by the Prompt Gamma Activation Analysis technique [14] in the Budapest Neutron centre (constituents in wt\%: $68.52 \mathrm{SiO}_{2}, 13.77$ $\mathrm{Na}_{2} \mathrm{O}, 8.19 \mathrm{CaO}, 4.34 \mathrm{MgO}, 1.003 \mathrm{Al}_{2} \mathrm{O}_{3}, 0.588 \mathrm{~K}_{2} \mathrm{O}, 0.105 \mathrm{Fe}_{2} \mathrm{O}_{3}$ and about $3.5 \%$ of other components).

\subsection{Procedure of ion exchange}

Glass samples were dipped in a molten salt bath formed by a mixture of $\mathrm{AgNO}_{3}$ and $\mathrm{NaNO}_{3}$ with molar ratio of 1:99, 5:90 and 10:90 for $60 \mathrm{~min}$ in crucible of $\mathrm{Al}_{2} \mathrm{O}_{3}$. The ion exchange has been carried out at a temperature of $320^{\circ} \mathrm{C}$ for $1 \mathrm{~h}$. During this step, the silver ions of the salt bath diffuse inside the glass matrix. The ion exchange samples are cleaned with distilled water and acetone to remove any silver nitrate adhering to their surface.

\subsection{Gamma irradiation and heat treatment}

Glass samples were irradiated at the Tunisian pilot plant ${ }^{60} \mathrm{Co}$ gamma irradiation facility [15] at a dose rate of $8.5 \mathrm{kGy} / \mathrm{h}$ and at room temperature with doses varying from 1 to $250 \mathrm{kGy}$.

Thermal annealing was performed in electrical furnace in air at the temperature of $550{ }^{\circ} \mathrm{C}$ for different time periods ranging from 10 to $582 \mathrm{~min}$.

\subsection{Optical absorption spectra}

Optical absorption spectra of the glass samples were measured in the range of $300-700 \mathrm{~nm}$ with a Shimadzu UV-VIS spectrophotometer (model PharmaSpec UV-1700). The measurements were carried out against a glass sample subjected neither to ion exchange nor to gamma irradiation.

\section{Results and discussion}

\subsection{Effect of ion-exchange}

Glass samples were subjected to ion exchange procedure, with molar ratio of $5: 95$, at a temperature of $320^{\circ} \mathrm{C}$ for $1 \mathrm{~h}$. After ion exchange, the absorption spectrum showed significant difference from that before the ion exchange. As illustrated in Fig. 1, the spectrum is characterized by a sharp asymmetrical absorption band located at $305 \mathrm{~nm}$. The asymmetric shape of this band may be due to the fact that the maximum measured does not match the maximum of the band but only to the loss of sensitivity of the spectrophotometer below $300 \mathrm{~nm}$.

When samples of silicate glass are immersed in molten silver nitrate, sodium ions diffuse from the glass surfaces to the molten salt, and silver ions diffuse from the molten salt to the glass surfaces where they replace sodium ions. The exchanged glass is colourless or very faint yellow state. Accordingly, changes in the

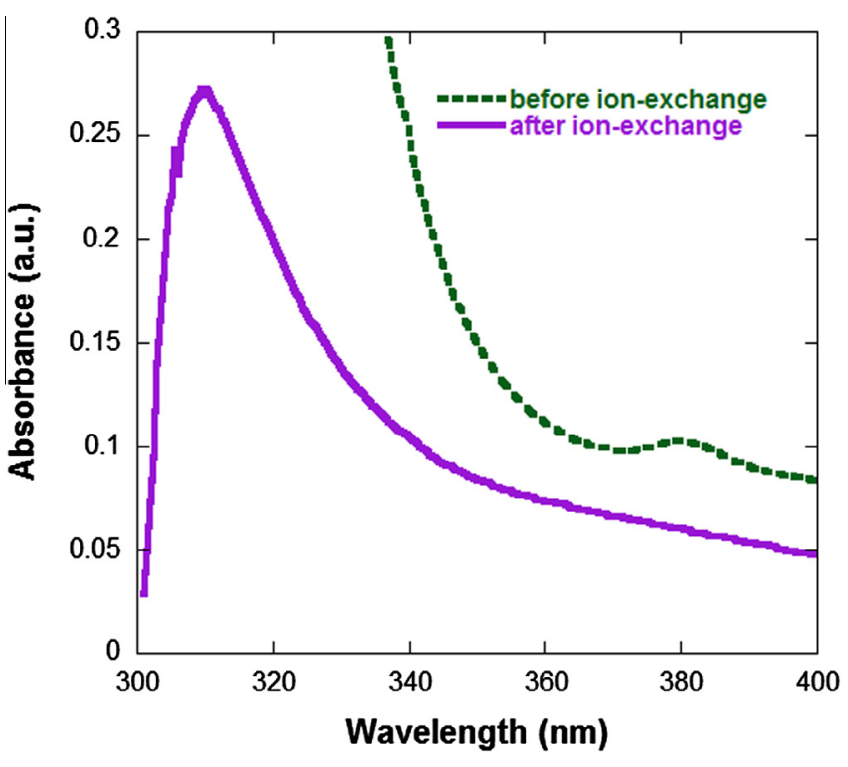

Fig. 1. Absorption optical spectra of silicate glass before and after ion-exchange.

spectrum of glass after ion exchange could be ascribed to modification of the composition of the glass surface by replacement of sodium ions by silver according to the reaction:

$\equiv \mathrm{Si}-\mathrm{O}-\mathrm{Na}^{+}+\mathrm{Ag}^{+} \mathrm{NO}_{3}^{-} \rightarrow \equiv \mathrm{Si}-\mathrm{O}-\mathrm{Ag}^{+}+\mathrm{Na}^{+} \mathrm{NO}_{3}^{-}$

The absorption band having a maximum at $305 \mathrm{~nm}$ was assigned to $\mathrm{Ag}^{+}$ion. The information available in the literature about the origin of this band was reviewed in details by Ahmed et al. [16] and Paje et al. [17].

\subsection{Effect of gamma irradiation}

Silver exchanged as well as non-exchanged silicate glass samples were gamma-irradiated to $250 \mathrm{kGy}$. Optical absorption spectra were measured several days after irradiation are shown Fig. 2. The

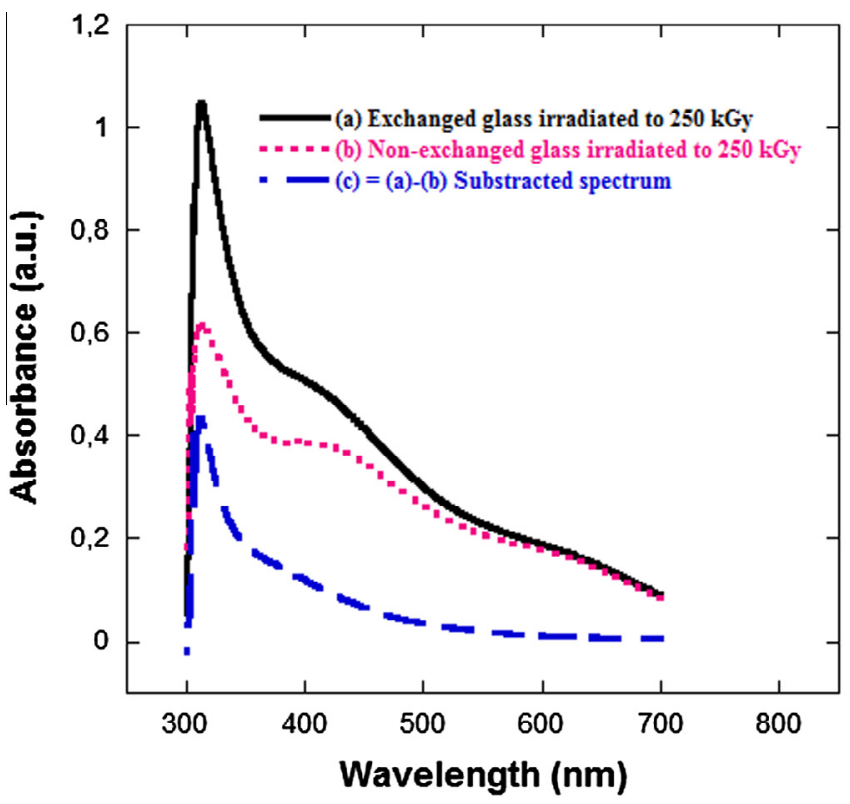

Fig. 2. Absorption spectra of the glass irradiated with $\gamma$ rays at $250 \mathrm{kGy}$ (a) spectrum of a $10 \% \mathrm{AgNO}_{3}$ exchanged glass; (b) spectrum of non-exchanged glass; $(\mathrm{c})=(\mathrm{a})-(\mathrm{b})$. 
Table 1

Gaussian fitting parameters of the optical spectrum (Fig. 2(b)) from non exchanged silicate glass after gamma irradiation at $250 \mathrm{kGy}$.

\begin{tabular}{lllll}
\hline $\begin{array}{l}\text { Peak } \\
\text { position }(\mathrm{nm})\end{array}$ & $\begin{array}{l}\mathrm{FWHM}^{\mathrm{a}} \\
(\mathrm{nm})\end{array}$ & $\begin{array}{l}\text { Area under } \\
\text { the band }\end{array}$ & $\begin{array}{l}\text { Max. absorbance } \\
\text { (u.a.) }\end{array}$ & Assignment \\
\hline 312 & 31.13 & 11.2 & 0.287 & $\mathrm{TE}$ \\
400 & 190.7 & 88.4 & 0.37 & $\mathrm{HC}_{1}$ \\
610 & 155 & 24.2 & 0.125 & $\mathrm{HC}_{2}$ \\
\hline
\end{tabular}

${ }^{a}$ FWHM is the full width at half maximum.

optical absorption spectrum of the non-exchanged sample (b) display overlapping three characteristic bands with maxima at about 312,400 and $610 \mathrm{~nm}$ respectively. Its spectrum was fitted by Gaussian curves whose parameters are given in Table 1. According to what reported by many authors $[18,19]$ the absorption bands at around 400 and at $610 \mathrm{~nm}$ have been attributed to "non-bridging oxygen hole centres" (NBOHCs : $\equiv \mathrm{Si}-\mathrm{O}^{*}$ ), where the trapped hole correlated to the absorption at $400 \mathrm{~nm}$ denoted as $\mathrm{HC}_{1}$ is a hole trapped in the $2 \mathrm{p}$ orbital of one and $\mathrm{HC}_{2}$ is a hole trapped on two or three non-bridging oxygen bonded to the same silicon and correlating absorption band around $610 \mathrm{~nm}$. The absorption band at about $312 \mathrm{~nm}$ have been attributed to trapped electrons (TE : “””) [20].

An additional absorption band was developed as a result of silver-exchange at about $354 \mathrm{~nm}$. This band has been evidenced by comparing the optical absorption spectrum of the non-exchanged glass to that of gamma-irradiated silver-exchanged glass (subtraction spectrum (c)). The characteristics of the subtracted spectrum were determined by Lorentzian adjustment (Table 2). This band was attributed by many authors $[10,21]$ to neutral silver atoms $\mathrm{Ag}^{0}$. The observation of neutral silver means that a fraction of the

Table 2

Lorentzian fitting parameters of subtracted spectrum (Fig. 2(c)).

\begin{tabular}{lccll}
\hline $\begin{array}{l}\text { Peak position } \\
(\mathrm{nm})\end{array}$ & $\begin{array}{l}\text { FWHM } \\
(\mathrm{nm})\end{array}$ & $\begin{array}{l}\text { Area of the } \\
\text { band }\end{array}$ & $\begin{array}{l}\text { Max. absorbance } \\
\text { (a.u.) }\end{array}$ & Assignment \\
\hline 315 & 19.4 & 9.4 & 0.31 & $\mathrm{Ag}_{2}^{+}$ \\
354 & 144.3 & 37.4 & 0.165 & $\mathrm{Ag}^{0}$ \\
\hline
\end{tabular}

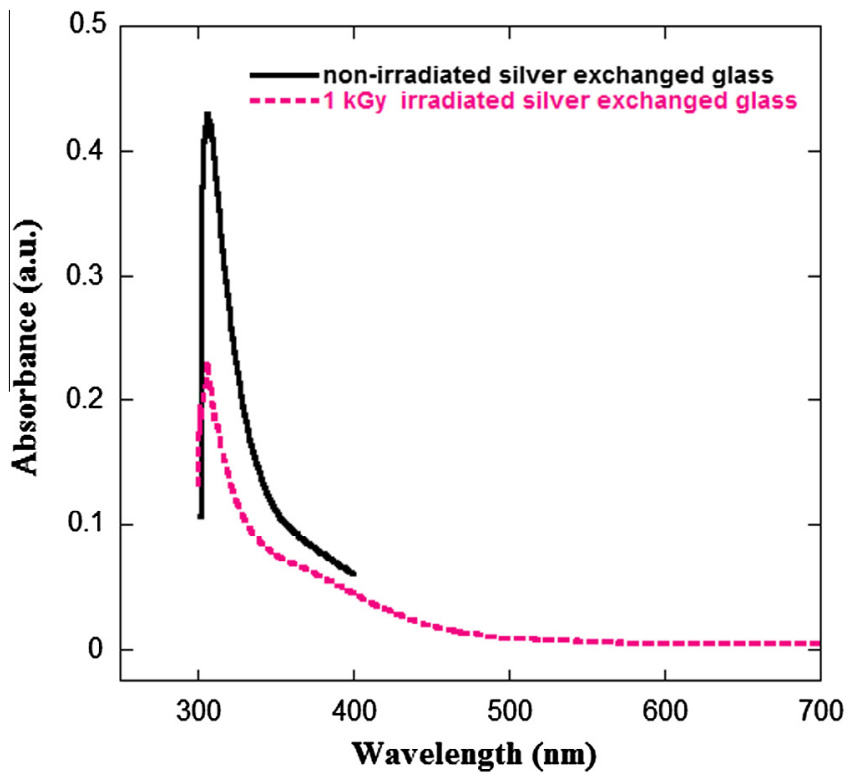

Fig. 3. Absorption spectra of ion-exchanged silicate glass $\left(10 \% \mathrm{AgNO}_{3}\right)$ and then irradiated at $1 \mathrm{kGy}$. photoelectron population has reduced silver ions directly by reactions:

$$
\begin{aligned}
& \text { Glass } \stackrel{\text { rrays }}{\rightarrow} h^{+}+e^{-} \\
& \mathrm{Ag}^{+}+e^{-} \rightarrow \mathrm{Ag}^{0}
\end{aligned}
$$

where $h^{+}$a hole is centre and $e^{-}$is an electron.

As shown in Fig. 3, irradiation of the silver exchanged sample at $1 \mathrm{kGy}$ led to the significant decrease of the intensity of the $\mathrm{Ag}^{+}$ band at $305 \mathrm{~nm}$ and the appearance of the new band at $354 \mathrm{~nm}$ assigned to $\mathrm{Ag}^{0}$.

\subsection{Effect of gamma irradiation and heat treatment}

The only effect of $\gamma$ irradiation at $250 \mathrm{kGy}$ and annealing at $550{ }^{\circ} \mathrm{C}$ for $60 \mathrm{~min}$ or their combined effects on glass samples exchanged at $1 \% \mathrm{AgNO}_{3}$ were shown in Fig. 4. A new absorption band appears around $430 \mathrm{~nm}$ in the spectra of the exchanged samples (b and c). According to several authors [6,8], this absorption peak corresponds to the Surface-Plasmon Resonance (SPR) of the silver aggregates in glass. The formation of these aggregates is due to diffusion and agglomeration of neutral silver atoms in the glass matrix during gamma irradiation and/or heat treatment according to the reaction:

$n \mathrm{Ag}^{0} \rightarrow \mathrm{Ag}_{n}$

For spherical aggregates, the average aggregate radius $R$ of is calculated from the FWHM, $\Delta \lambda$ of the optical absorption peak using the formula:

$R=\frac{V_{f} \cdot \lambda_{m}^{2}}{2 \pi \Delta \lambda}$

where $V_{f}$ is the Fermi velocity of the electron in the bulk metal (silver $=1.39 \times 108 \mathrm{~cm} / \mathrm{s}$ ), $\Delta \lambda$ is the full width at half maximum of the absorption band (FWHM) and $\lambda_{m}$ is the characteristic wavelength at which SPR occurs.

We clearly observe that the spectrum (c) has a FWHM much narrower than that of the spectrum (b), the maximum absorbance is increased by a factor of 2 and the peak position is blueshifted from 430 to $421 \mathrm{~nm}$ (Table 3). It is also seen in Table 3 that

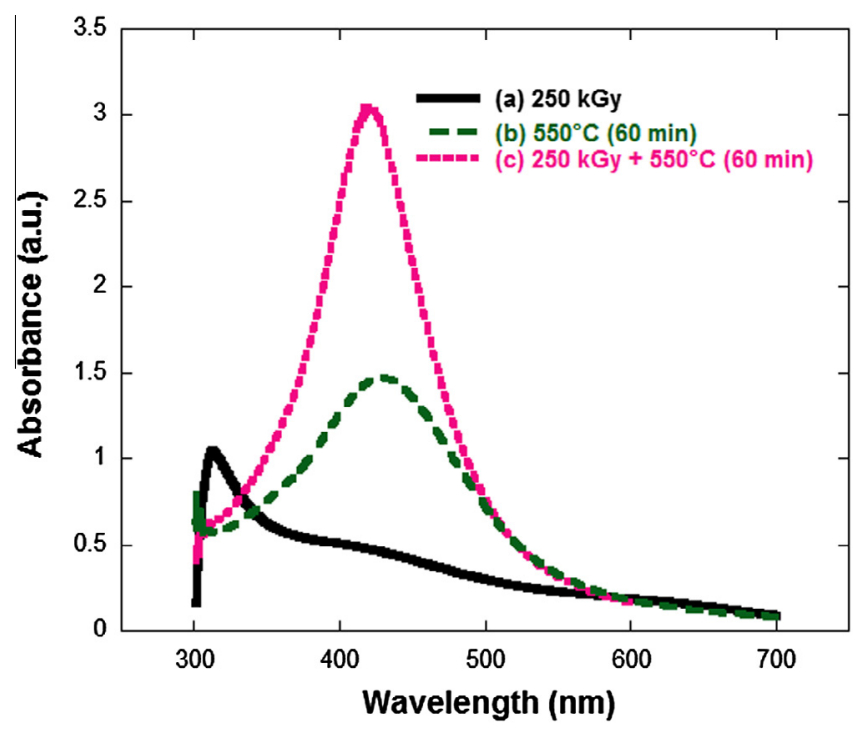

Fig. 4. Absorption spectra of ion-exchanged silicate glass, under the following conditions: (a) irradiated with $\gamma$ rays at $250 \mathrm{kGy}$; (b) annealed at $550{ }^{\circ} \mathrm{C}$ for $60 \mathrm{~min}$; and (c) irradiated at $250 \mathrm{kGy}$ and annealed at $550{ }^{\circ} \mathrm{C}$ for $60 \mathrm{~min}$. 
Table 3

Characteristics of the plasmon resonance band, obtained by Lorentzian fitting, of two glass samples exchanged at $1 \% \mathrm{AgNO}_{3}$ and subjected to different treatments.

\begin{tabular}{|c|c|c|c|c|}
\hline Treatment undergone by the glass sample & Peak position $(\mathrm{nm})$ & FWHM (nm) & Max. absorbance (u.a.) & Average radius of the cluster (nm) \\
\hline Annealed at $550{ }^{\circ} \mathrm{C}$ for $60 \mathrm{~min}$ & 429.6 & 140.3 & 1.48 & 0.97 \\
\hline Irradiated at $250 \mathrm{kGy}$ and annealed at $550^{\circ} \mathrm{C}$ for $60 \mathrm{~min}$ & 421.4 & 94.0 & 2.99 & 1.40 \\
\hline
\end{tabular}

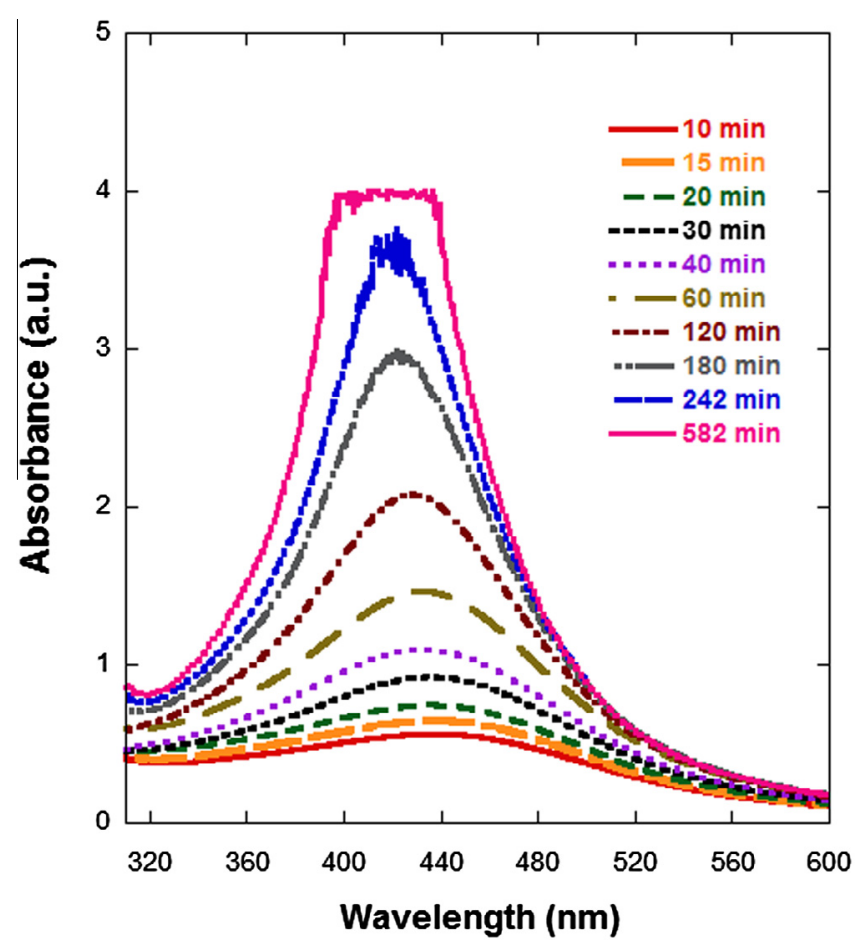

Fig. 5. Absorption spectra of ion-exchanged silicate glass, irradiated with $\gamma$ rays at $250 \mathrm{kGy}$ and annealed at $550{ }^{\circ} \mathrm{C}$ for the indicated times.

aggregate size increased significantly by about $43 \%$ in the irradiated sample. The increase in intensity of the absorption band in the irradiated sample is attributed to the increase in the total number of silver atoms constituting the aggregates. The conventional synthesis of silver nanoparticles in ion-exchanged glass requires the action of reducing agents present in the glass and enhanced diffusivity which is achieved only by thermal treatment at temperature well above $450^{\circ} \mathrm{C}$. By this procedure, only a few percent of the $\mathrm{Ag}^{+}$ions introduced are converted to silver atoms [8]. The improved formation process of silver nanoparticles by gamma

Table 4

Characteristics of the plasmon resonance band as a function of annealing time at $550{ }^{\circ} \mathrm{C}$, obtained by Lorentzian fitting, of glass samples exchanged to $5 \% \mathrm{AgNO}_{3}$ and irradiated to $250 \mathrm{kGy}$.

\begin{tabular}{cllll}
\hline $\begin{array}{l}\text { Annealing time } \\
(\mathrm{min})\end{array}$ & $\begin{array}{l}\text { Peak position } \\
(\mathrm{nm})\end{array}$ & $\begin{array}{l}\text { FWHM } \\
(\mathrm{nm})\end{array}$ & $\begin{array}{l}R^{\mathrm{a}} \\
(\mathrm{nm})\end{array}$ & $\begin{array}{l}\text { Area under band } \\
(\text { a.u. })\end{array}$ \\
\hline 10 & 439.71 & 161.00 & 0.89 & 145.42 \\
15 & 439.77 & 153.72 & 0.93 & 158.16 \\
20 & 438.44 & 151.72 & 0.94 & 180.89 \\
30 & 437.95 & 143.20 & 0.99 & 211.44 \\
40 & 435.57 & 137.20 & 1.02 & 240.51 \\
60 & 434.18 & 127.60 & 1.09 & 297.44 \\
120 & 426.98 & 116.82 & 1.15 & 381.50 \\
182 & 422.94 & 101.18 & 1.31 & 465.83 \\
242 & 421.3 & 91.82 & 1.43 & 523.56 \\
582 & 417.7 & 87.76 & 1.47 & 591.39 \\
\hline
\end{tabular}

a The average aggregate radius $R$. irradiation is explained by the fact that the diffusion of silver in the glass increases by several orders of magnitude when the sample is irradiated by gamma rays before undergoing heat treatment.

The gamma irradiation with $250 \mathrm{kGy}$ of ion-exchange silicate glass was followed by annealing at the temperature of $550{ }^{\circ} \mathrm{C}$ for different time periods ranging from 10 to $582 \mathrm{~min}$ (Fig. 5). The intensity (or area under the band), shape and peak position of the absorption band at about $440 \mathrm{~nm}$ were found to be significantly by the increase of the annealing time.

The characteristics of this band as a function of increasing annealing time, obtained by Lorentzian fitting, are shown in Table 4 . The area under the peak increases with increasing annealing time and its peak position is blueshifted from 440 to $418 \mathrm{~nm}$. At the same time the band becomes more sharp, the full width at half maximum (FWHM) decrease from 161 to $88 \mathrm{~nm}$.

Since this band has been associated with the formation of silver aggregates, it is expected that changes in the shape and size of theses aggregates induced by increasing of annealing time would affect the position, intensity or area under the band and FWHM of the induced absorption band. With increasing of annealing time, the number of neutral silver atoms increased leading to the increase in the number and dimensions of the aggregates. In Fig. 6 the proportionality between aggregates radius and area under the band is shown. This result is in good agreement with data published by Doremus [6]. Indeed, the total amount of silver constituting the aggregates was described by Doremus to be proportional to the area under the band. The proportionality between the reciprocal of the absorption band width and the radius of silver aggregates was also evidenced by Doremus, as long as the size distribution of the aggregates is narrow. Accordingly, Doremus attribute this absorption band to very small, spherical silver aggregates. If the aggregates were not spherical, the absorption peak position would be at longer wavelengths and would gradually shift to shorter wavelengths as the aggregates become more spherical with increasing time of annealing.

The dependence of the FWHM and the peak position of the absorption band on the size and the shape (eccentricity of the ellipsoid) of aggregate were also studied by Mennig and Berg [22]. They found that the FWHM is heavily dependent on the aggregate size but nearly independent of the (shape and the peak positions are significantly dependent on aggregate shape but nearly independent of the size.

The aggregates radius is plotted as a function of annealing time in Fig. 7. We observe that the aggregates radius grew between 0.9 and $1.43 \mathrm{~nm}$ with increasing of annealing time from 10 to $242 \mathrm{~min}$ and then saturated. Kowal et al. [8] suggest that the saturation of the absorption band for long annealing times may be due to the fact that all silver ions embedded in the samples have yet been reduced.

On the other hand, the precipitation of silver decreases the energy system, and therefore the silver atoms tend to precipitate to form aggregates [23]. The aggregation is accelerated at elevated temperature $\left(550{ }^{\circ} \mathrm{C}\right.$ ) and continued growth by increasing of the annealed time up to critical size.

TEM images (Transmission Electron Microscopy) performed by Zhang et al. [11] on a silicate glass ion-exchanged to $2 \% \mathrm{AgNO}_{3}$ and annealed, show that the distances between neighboring aggregates remains high. Accordingly, once the precipitation completed, 


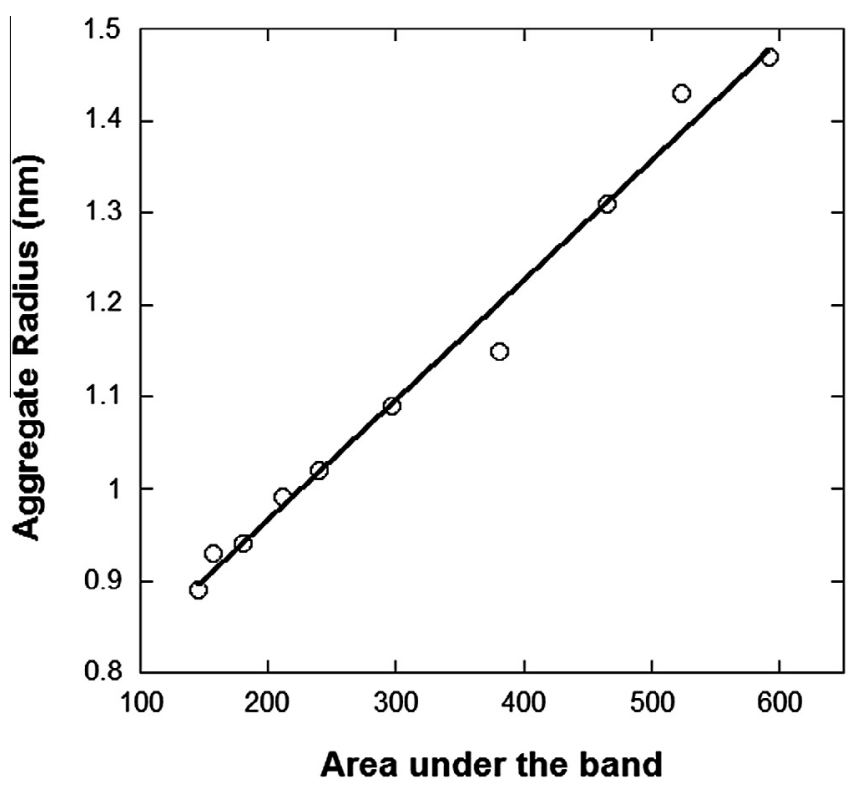

Fig. 6. Average aggregate radius as a function of area under the SPR absorption band.

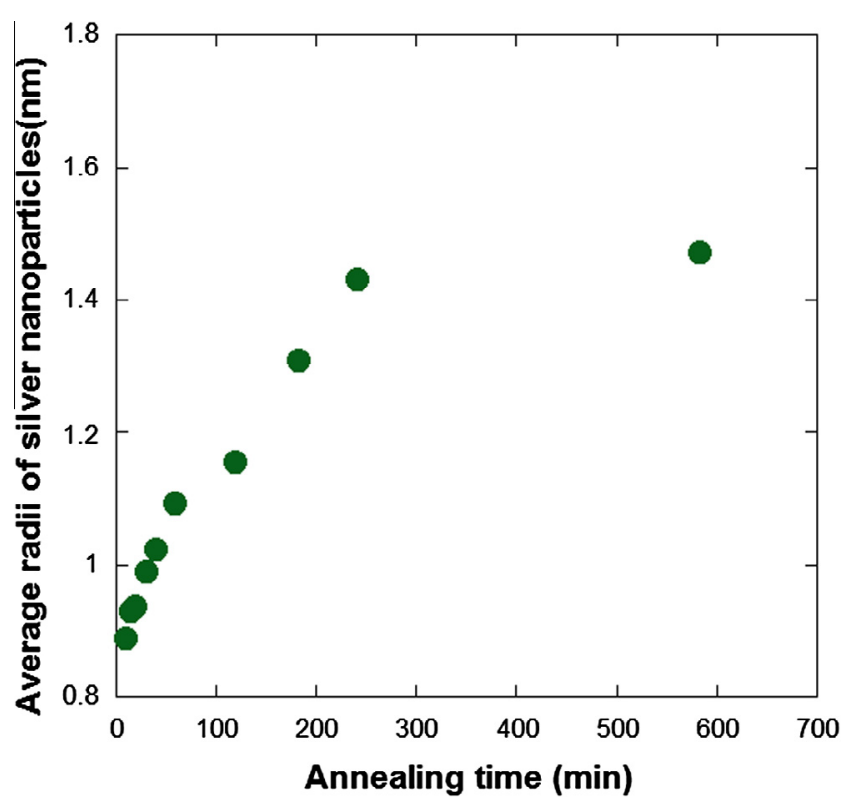

Fig. 7. Growth of silver aggregates as a function of annealed time $\left(550{ }^{\circ} \mathrm{C}\right)$ in a glass exchanged to $5 \% \mathrm{AgNO}_{3}$ and irradiated by $\gamma$ radiation to $250 \mathrm{kGy}$.

an aggregate of larger size cannot grow by intergranular diffusion process. These images show also that the aggregates have a spherical shape.

\subsection{Effect of absorbed doses}

In order to investigate the effect of absorbed dose variation on the characteristics of the absorption band attributed to the SPR, glasses samples exchanged at $1 \% \mathrm{AgNO}_{3}$ were irradiated in the dose range of 1-100 kGy. The samples were then annealed at $550{ }^{\circ} \mathrm{C}$ for $60 \mathrm{~min}$. The results are shown in (Fig. 8). It shows that, for a dose of $1 \mathrm{kGy}$, the absorption spectrum appear to be due to the superposition of two absorption bands around 350 and
$450 \mathrm{~nm}$. However, when the dose exceeds $1 \mathrm{kGy}$, the band at $350 \mathrm{~nm}$ disappears and that at $450 \mathrm{~nm}$ has good resolution. The characteristics of this band as a function of increasing dose, obtained by Lorentzian fitting, are shown in Table 5 .

For doses below $20 \mathrm{kGy}$, we observed a shift of the absorption peak to shorter wavelengths (from about 448 to $425 \mathrm{~nm}$ ), a significant increase in its area under the absorption band (or intensity) and a reduction in its FWHM (from about 172 to $103 \mathrm{~nm}$ ). It is also noted that these changes can be related to the increase in aggregate size as it has been shown previously. As well, no significant variation in the peak position was recorded for doses above $5 \mathrm{kGy}$, indicating that increasing absorbed doses above this limit has no effect on the shape of the aggregates. As mentioned previously $[6,22]$, the peak position depends largely on the aggregate shape, while the FWHM depends mainly on the aggregate size. Therefore, perfectly spherical aggregates could be synthesized by irradiation at this dose level.

In other hand, based on spectroscopic calculations and data and electron microscopic studies, many authors [6,16,22] confirm that silver aggregates formed in glass treated by irradiation and/or heat treatment, which develop only a single absorption band, are spherical and very small size.

Moreover, it is noteworthy that for doses above $20 \mathrm{kGy}$, an important reduction in the area under the absorption band and

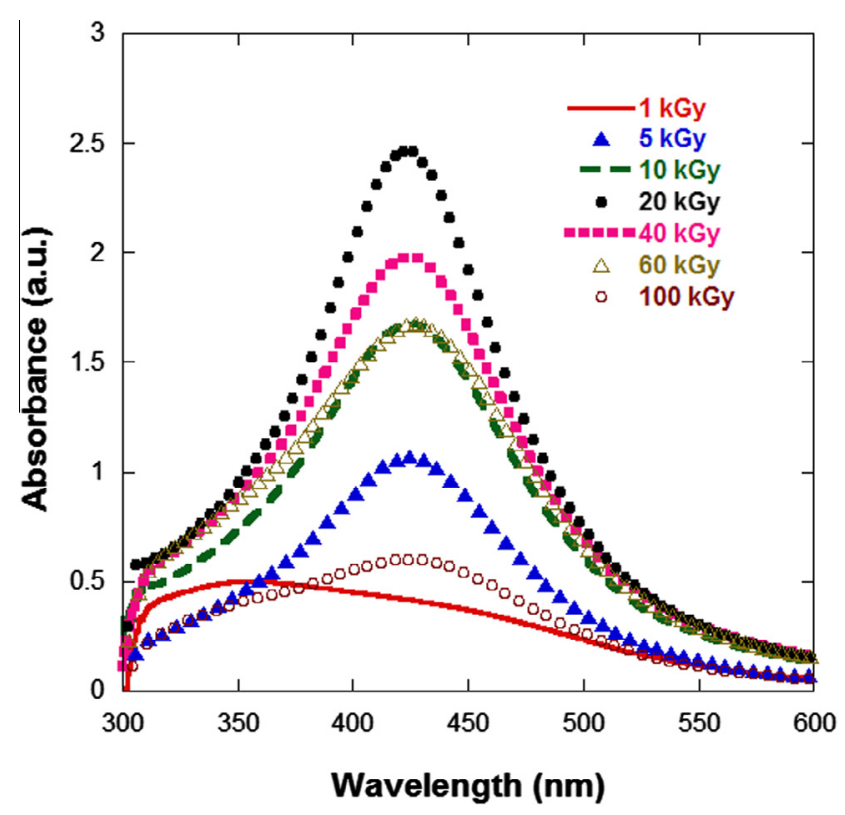

Fig. 8. Absorption spectra of ion-exchanged silicate glass, irradiated with $\gamma$ rays in the dose range of $1-100 \mathrm{kGy}$ and annealed at $550{ }^{\circ} \mathrm{C}$ for $60 \mathrm{~min}$.

Table 5

Characteristics of the plasmon resonance band as a function of gamma irradiation dose, obtained by Lorentzian fitting, of glass samples exchanged to $1 \% \mathrm{AgNO}_{3}$.

\begin{tabular}{cllll}
\hline $\begin{array}{l}\text { Dose } \\
(\mathrm{kGy})\end{array}$ & $\begin{array}{l}\text { Peak position } \\
(\mathrm{nm})\end{array}$ & $\begin{array}{l}\text { FWHM } \\
(\mathrm{nm})\end{array}$ & $\begin{array}{l}R^{\text {a }} \\
(\mathrm{nm})\end{array}$ & $\begin{array}{l}\text { Area under band } \\
(\text { a.u. })\end{array}$ \\
\hline 1 & 448.03 & 171.86 & 0.86 & 101.50 \\
5 & 425.5 & 122.64 & 1.09 & 205.93 \\
10 & 427 & 121.46 & 1.11 & 319.38 \\
20 & 425 & 103.46 & 1.29 & 401.41 \\
40 & 426.5 & 118.54 & 1.14 & 368.49 \\
60 & 428 & 132.22 & 1.03 & 347.67 \\
100 & 422.5 & 155.40 & 0.85 & 146.95 \\
\hline
\end{tabular}

a The average aggregates radius $R$. 


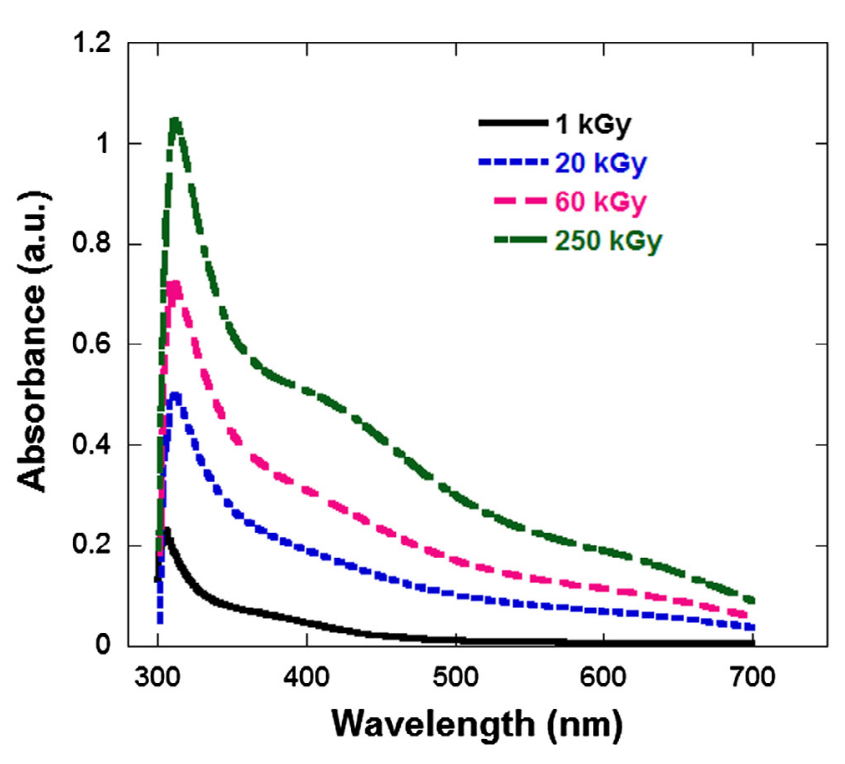

Fig. 9. Absorption spectra of ion-exchanged silicate glass $\left(10 \% \mathrm{AgNO}_{3}\right)$ and gamma irradiated at doses $1 ; 20 ; 60$ and $250 \mathrm{kGy}$.

an increase in its FWHM, from about 103 to $155 \mathrm{~nm}$, were observed. These observations can be explained by the partial neutralization of silver by $\gamma$ radiation in a first step $(D \leqslant 20 \mathrm{kGy})$. The increasing of the absorbed dose resulted in the observation of the first stage of silver aggregation, after irradiation and before the heat treatment, in silver ion exchanged silicate glass by converting $\mathrm{Ag}^{+}$ions into $\mathrm{Ag}_{2}^{+}$by the reaction:

$\mathrm{Ag}^{0}+\mathrm{Ag}^{+} \rightarrow \mathrm{Ag}_{2}^{+}$

The decrease in the area under the absorption band (or intensity) and the increase of its FWHM from 20 to $100 \mathrm{kGy}$ can be explained by the decrease of $\mathrm{Ag}^{0}$ concentration.

Because for doses $D>20 \mathrm{kGy}$, neutral silver atoms $\left(\mathrm{Ag}^{0}\right)$ formed by reduction of $\mathrm{Ag}^{+}$(reaction 2), convert to $\mathrm{Ag}_{2}^{+}$ions (reaction 6 ). It seems that for doses below $20 \mathrm{kGy}$ the concentration of $\mathrm{Ag}^{0}$ is not sufficient to activate the conversion reaction 6 .

Evidence for $\mathrm{Ag}_{2}^{+}$ions was found in optical absorption spectra of gamma-irradiated silver ion-exchanged silicate glass samples between 1 and $250 \mathrm{kGy}$, as shown in Fig. 9, in which the absorption peak is red shifted from $305 \mathrm{~nm}$ (the characteristic wavelength of $\mathrm{Ag}^{+}$) to $312 \mathrm{~nm}$ for absorbed doses above $1 \mathrm{kGy}$. We ascribed this $312 \mathrm{~nm}$ peak to $\mathrm{Ag}_{2}^{+}$; its position is identical to that found for $\mathrm{Ag}_{2}^{+}$in radiolyzed aqueous solutions containing $\mathrm{Ag}^{+}$ [21]. This peak was also identified by De Lamaëstre [9] at the same wavelength in a silicate glass doped with silver at a concentration of $118 \mathrm{ppm}$, irradiated to $21 \mathrm{kGy}$ and annealed at $150{ }^{\circ} \mathrm{C}$ for $30 \mathrm{~min}$.

\section{Conclusion}

In this work, we reported a study on the formation of nanoparticles in silicate glass using combined techniques. Silverdoped glass was obtained by $\mathrm{Ag}^{+}-\mathrm{Na}^{+}$ion-exchange process. Glass samples were then subjected to gamma rays and/or to thermal annealing in air.

Silver nanoparticles have been characterized using UV-Visible absorption spectroscopy. The gamma irradiation induced hole centres and electrons in the glass matrix leading to creation of brown colour, and silver ions trapped electrons to form silver atoms. The silver atoms diffused and then aggregate to form nanoparticles after annealing at $550^{\circ} \mathrm{C}$ for different time periods ranging from 10 to $582 \mathrm{~min}$. A characteristic band at $430 \mathrm{~nm}$ was induced. The nanoparticles grew between 0.9 and $1.43 \mathrm{~nm}$ with increasing of annealing time between 10 and $242 \mathrm{~min}$ and then saturated.

The formation process of silver nanoparticles is improved if the samples were irradiated before undergoing thermal annealing because gamma irradiation increases the diffusivity of silver in the glass by several orders of magnitude.

\section{References}

[1] T.P. Seward, J. Non-Cryst. Solids 40 (1980) 499-513.

[2] L.A. Ageev, V.K. Miloslavskiî, E.D. MakovetskiǏ, Opt. Spectrosc. 102 (2007) 442448.

[3] J.H. Schulman, R.J. Ginther, C.C. Klick, R.S. Alger, R.A. Levy, J. Appl. Phys. 22 (1951) 1479-1487.

[4] H. Bach, N. Neuroth, The Properties of Optical Glass, Springer, Berlin, 1998.

[5] R.H.J. Doremus, Chem. Phys. 40 (1964) 2389-2396.

[6] R.H.J. Doremus, Chem. Phys. 42 (1965) 414-417.

[7] D. Manikandan, S. Mohan, P. Magudapathy, K.G.M. Nair, Phys. B 325 (2003) 8691.

[8] Kowal et al., Nucl. Instrum. Methods B 166-167 (2000) 490-494.

[9] H. Hofmeister, S. Thiel, M. Dubiel, E. Schurig, Appl. Phys. Lett. 70 (1997) 16941696.

[10] R. Espiau de Lamaestre, H. Béa, H. Bernas, J. Belloni, J.L. Marignier, Phys. Rev. B 76 (2008) 205431.

[11] J. Zhang, W. Dong, J. Sheng, J. Sheng, J. Zheng, J. Li, L. Qiao, L. Jiang, J. Cryst. Growth 310 (2008) 234-239.

[12] K. Farah, A. Mejri, F. Hosni, A.H. Hamzaoui, B. Boizot, Current Topics in Ionizing Radiation Research, vol. 28, Croatia InTech Open Access Publisher, 2012, pp. 603-624.

[13] Farah, K., Mejri, A., Ben Ouada, H. Fundamental, Applied Spectroscopy, AIP Conference Proceedings, vol. 935, Melvile, New York, 2007, pp. 231-236.

[14] D.L. Anderson, T. Belgya, R.B. Firestone, Zs. Kasztovsky, R.M. Lindstom, G.L. Molnàr, Zs. Révay, C. Yonezawa, Handbook of Prompt Gamma Activation Analysis, Kluwer Academic Publishers, Dordrecht, The Netherlands, 2004.

[15] K. Farah, T. Jerbi, F. Kuntz, A. Kovacs, Radiat. Meas. 41 (2006) 201-208.

[16] A.A. Ahmed, E.W. Abd-Allah, J. Am. Ceram. Soc. 78 (1995) 2777-2784.

[17] S.E. Paje, M.A. García, P. Llopis, M.A. Villegas, J. Non-Cryst. Solids 318 (2003) 239-247.

[18] J.W.H. Schreurs, J. Chem. Phys. 47 (1967) 818-829.

[19] D.L. Griscom, J. Non-Cryst. Solids 64 (1984) 229-247.

[20] C.D. Marshall, J.A. Speth, S.A. Payne, J. Non-Cryst. Solids 212 (59-73) (1997) 621-626.

[21] J. Bellouni, M. Mostafavi, Nucleation Mechanisms and Chemistry, in: P. Braunstein, L.A. Oro, P.R. Raithby (Eds.), Wiley-VCH Verlag GmbH, Weinheim, Germany, 1999, p. 1213.

[22] M. Mennig, K.J. Berg, Mater. Sci. Eng. B9 (1991) 421-424.

[23] P.W. Wang, Appl. Surf. Sci. 120 (1997) 291-298. 